\title{
Содержание хлорофилла «а» в планктоне озер урбанизированных территорий Мурманской области
}

Денисов Д.Б. ${ }^{1}$, Слуковский 3.И., ${ }^{1,2}$ Косова А.Л. ${ }^{1}$

${ }^{1}$ Институт проблем промышленной экологии Севера КНЦ РАН, Anamumbl,proffessuir@gmail.com

${ }^{2}$ Институт геологии КарНЦ РАН, Петрозаводск, slukovsky87@gmail.com

Аннотация. В статье представлена информация о содержании хлорофилла «а» в планктоне 19 разнотипных водоемов, расположенных на территории трех урбанизированных районов Мурманской области - пгт Никель, г. Мончегорск и г. Мурманск. Средняя летняя концентрация хлорофилла «а» в большинстве водоемов на порядок превышает региональные фоновые показатели. Показано, что загрязнение вод токсичными тяжелыми металлами $(\mathrm{Cu}, \mathrm{Ni})$ приводит к угнетению фотосинтеза фитопланктона и олиготрофизации вод, несмотря на высокое содержание соединений биогенных элементов. В условиях мощного антропогенного эвтрофирования и сравнительно невысокого содержания токсичных металлов в воде, содержание хлорофилла «a» достигает экстремальных для арктической зоны значений - до 45.3 мг/л.

Ключевые слова: хлорофилл «а»; фитопланктон; урбанизированные территории; арктические озера.

\section{Chlorophyll «a» in the lakes in urban territories of the Murmansk region}

\author{
Denisov D.B. ${ }^{1}$, Slukovskii Z.I. ${ }^{1,2}$, Kosova A.L. ${ }^{1}$ \\ ${ }^{1}$ Institute of the North Industrial ecological problems KSC RAS, Apatity,proffessuir@gmail.com \\ ${ }^{2}$ Institute of Geology KarRS RAS, Petrozavodsk, slukovsky87@gmail.com
}

\begin{abstract}
Information about the chlorophyll «a» content in plankton of 19 different types of lakes located on the three urbanized territories of the Murmansk region - the towns Nikel, Monchegorsk and the Murmansk city is presented. The average summer concentration of chlorophyll a in much lakes is much higher than regional background values. The toxic heavy metals pollution leads to inhibition of phytoplankton photosynthesis and water oligotrophization despite the high content of nutrients. Otherwise, the powerful anthropogenic eutrophication with the relatively low content of toxic metals in water causes the extreme for the Arctic chlorophyll «a» values - up to $45.3 \mathrm{mg} / \mathrm{l}$.
\end{abstract}

Key words: chlorophyll " $a$ "; phytoplankton; urban territories; Arctic lakes.

\section{Введение}

Содержание хлорофилла «a» (Chl «а») в планктоне является одним из важнейших критериев при оценке трофического статуса, служит показателем физиологического состояния водорослей и позволяет оценить их продукционный потенциал. Количественные показатели Chl «a» дают возможность оценить состояние первого трофического уровня водных экосистем и степень трансформации водоема под влиянием антропогенных факторов. Исследования концентрации Chl «a» в арктических регионах зачастую являются единственным источником достоверной информации о развитии и функционировании водорослевых сообществ в условиях непродолжительного периода вегетации. Водные объекты урбанизированных территорий Мурманской области подвергаются разнообразному антропогенному воздействию, чаще всего проявляющемуся в экстремальных уровнях загрязнения воды и донных отложений (Kashulin et al., 2017; Слуковский и др., 2018; Слуковский, Даувальтер, 2019; Денисов и др., 2018). Информация о содержании Chl «a» для городских водоемов региона в настоящее время не является исчерпывающей (Денисов и др. 2009; Денисов, 2019), в то время как учет этого показателя необходим для адекватной оценки качества вод при реализации программ комплексного экологического мониторинга городской среды.

\section{материал и методы}

Объектами исследования послужили разнотипные водоемы, расположенные на урбанизированных территориях Мурманской области (пгт Никель, г. Мончегорск и г. Мурманск). Были обследованы водоемы, расположенные непосредственно в городской черте и на прилегающих террито- 
риях (табл. 1). На сравнительно крупном оз. Куэтсъярви исследования проводились на четырех различных участках акватории. Отбор проб был проведен в августе: на озерах в районе пгт Никель (2016-2019 гг.), г. Мончегорска (2017-2019 гг.) и г. Мурманска (2018-2019 гг.); всего изучено 19 водоемов. Для определения концентрации пигментов пробы воды объемом 600 мл фильтровались через мембранный фильтр с диаметром пор 0.47 мкм с помощью шприца Millipore с фильтровальной насадкой. Фильтрация производилась непосредственно на водоеме, чтобы избежать изменений содержания фотосинтетических пигментов при транспортировке проб воды. Экстракция хлорофилла проводилась раствором ацетона (90 \%, ЧДА), оптическая плотность экстрактов измерялась на спектрофотометрах Hitachi UV-VIS 181 и ПЭ-5400УФ. Концентрацию Chl «a» рассчитывали стандартными общепринятыми в мировой и отечественной практике методами (Determination, 1996; Минеева, 2004; Методы..., 2019). Трофический статус вод по содержанию Chl «а» оценивался по шкале, предложенной С.П. Китаевым (2007). Гидрохимический анализ проб воды был выполнен в аналитической лаборатории Института проблем промышленной экологии Севера Кольского НЦ РАН и Аналитического центра Института геологии Карельского НЦ РАН.

Таблица 1. Некоторые характеристики исследованных озер и координаты станций отбора проб (2016-2019 гг.).

Table 1. Selected parameters of the studied lakes and sampling points coordinates (2016-2019).

\begin{tabular}{|c|c|c|c|c|c|}
\hline & \multicolumn{2}{|l|}{ Озеро } & Координаты, DD & Площадь зеркала, км² & Высота над у.м., м \\
\hline \multirow{6}{*}{ 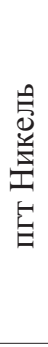 } & \multirow{4}{*}{ Куэтсъярви } & 1 & N69,397881 ${ }^{\circ}$ E30,147166 & \multirow{4}{*}{17.00} & \multirow{4}{*}{21} \\
\hline & & 2 & $\mathrm{~N} 69,475992^{\circ} \mathrm{E} 30,247931^{\circ}$ & & \\
\hline & & 3 & N69,432622 ${ }^{\circ} \mathrm{E} 30,163559^{\circ}$ & & \\
\hline & & 4 & $\mathrm{~N} 69,476902^{\circ} \mathrm{E} 30,200381^{\circ}$ & & \\
\hline & \multicolumn{2}{|l|}{ LN2 } & $\mathrm{N} 69,425629^{\circ} \mathrm{E} 30,395393^{\circ}$ & 0.12 & 203 \\
\hline & \multicolumn{2}{|l|}{ LN3 } & N69,436606 ${ }^{\circ}$ E30,582285 & 0.07 & 275 \\
\hline \multirow{6}{*}{ 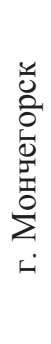 } & \multicolumn{2}{|c|}{ Пыслысчимъявр } & N67,899434 E32,885905 & 0.49 & 136 \\
\hline & \multicolumn{2}{|l|}{ Сопчъявр } & N67,895461 ${ }^{\circ} \mathrm{E} 32,786255^{\circ}$ & 1.36 & 172 \\
\hline & \multicolumn{2}{|l|}{ Кумужье } & $\mathrm{N} 67,939143^{\circ} \mathrm{E} 32,797229^{\circ}$ & 0.25 & 187 \\
\hline & \multicolumn{2}{|l|}{ Нюдъявр } & N67,927156 ${ }^{\circ} \mathrm{E} 32,885390^{\circ}$ & 3.78 & 128 \\
\hline & \multicolumn{2}{|l|}{ Травяное } & N67,942496 ${ }^{\circ}$ E32,845637 & 0.46 & 132 \\
\hline & \multicolumn{2}{|c|}{ Комсомольское } & $\mathrm{N} 67,936093^{\circ} \mathrm{E} 32,950107^{\circ}$ & 0.12 & 138 \\
\hline & \multicolumn{2}{|l|}{ Семеновское } & N68,990947 E33,089276 & 0.21 & 96 \\
\hline & \multicolumn{2}{|l|}{ Северное } & N69,032941 ${ }^{\circ} \mathrm{E} 33,117815^{\circ}$ & 0.01 & 123 \\
\hline 馬 & \multicolumn{2}{|l|}{ Среднее } & $\mathrm{N} 68,981280^{\circ} \mathrm{E} 33,122802^{\circ}$ & 0.25 & 101 \\
\hline$\stackrel{2}{2}$ & \multicolumn{2}{|l|}{ Ледовое } & $\mathrm{N} 68,932911^{\circ} \mathrm{E} 33,103905^{\circ}$ & 0.04 & 73 \\
\hline$\sum$ & \multicolumn{2}{|l|}{ Треугольное } & $\mathrm{N} 68,968299^{\circ} \mathrm{E} 33,002683^{\circ}$ & 0.02 & 121 \\
\hline & \multicolumn{2}{|l|}{ Окуневое } & N68,951680 ${ }^{\circ} \mathrm{E} 33,130978^{\circ}$ & 0.05 & 99 \\
\hline & \multicolumn{2}{|l|}{ Южное } & N68,884336 ${ }^{\circ} \mathrm{E} 33,075748^{\circ}$ & 0.05 & 89 \\
\hline
\end{tabular}

\section{Результаты и обсуждение}

Химический состав вод исследованных водоемов существенно различается между собой и определяется типом и интенсивностью антропогенной нагрузки (табл. 2). Так, водоемы в районе пгт Никель и г. Мончегорска подвержены интенсивному загрязнению предприятиями металлургической промышленности АО «Кольская ГМК» (ПАО ГМК «Норильский никель»): содержание Сu и Ni в воде на 2-3 порядка превышает региональные фоновые показатели. В озерах г. Мурманска и прилегающих территорий концентрация металлов-загрязнителей не столь высока, но также много- 
кратно превышает фон. В изученных озерах зафиксировано сравнительно высокое содержание биогенных элементов - соединений азота и фосфора.

Содержание $\mathrm{Chl}$ «a» в планктоне в большинстве исследованных озер не превышало 3.0 мг/л, при этом в некоторых были выявлены экстремально высокие для арктических вод значения (рис.). Максимальные концентрации оказались характерны для водоемов г. Мурманска, расположенных непосредственно в городской черте: Семеновское и Ледовое - 8.1 и 45.3 мг/л; минимальные - для озер в районе пгт Никель: LN2 и LN3 - 0.7 и 0.3 мг/л соответственно. Фоновыми значениями среднего содержания Chl «a» для озер Кольского полуострова считается 0.2-0.3 мг/л (Никулина, 1975). Во всех исследованных озерах этот показатель оказался на порядок выше, что характерно для водоемов урбанизированных территорий Мурманской области (Денисов и др., 2018; Черепанов и др., 2019). Трофический статус вод, оцениваемый по среднему содержанию Chl «a» в планктоне большинства исследованных озер не превышает $\beta$-олиготрофного, даже для водоемов, где высока концентрация биогенных элементов. Это объясняется значительным уровнем загрязнения вод тяжелыми металлами, ингибирующими фотосинтетические процессы, при этом наиболее доступные водорослями соединения азота в виде нитратов не утилизируются фитопланктоном (Баринова и др., 2018).

Таблица 2. Некоторые среднелетние гидрохимические показатели исследованных водоемов (2016-2019 гг.).

Table 2. Selected mid-summer hydrochemical parameters of the studied lakes (2016-2019).

\begin{tabular}{|c|c|c|c|c|c|c|c|c|}
\hline & \multicolumn{2}{|l|}{ Озеро } & $\mathrm{pH}$ & $\begin{array}{l}\mathrm{P}_{\text {обш, }} \\
\text { мКг/л }\end{array}$ & $\begin{array}{c}\mathrm{N}_{\text {общ’ }}, \\
\text { мкГN/л }\end{array}$ & $\begin{array}{c}\mathrm{NO}_{3}, \\
\text { мкгN/л }\end{array}$ & $\begin{array}{c}\mathrm{Cu}, \\
\text { мкг/л }\end{array}$ & $\begin{array}{c}\mathrm{Ni}, \\
\text { мкг/л }\end{array}$ \\
\hline \multirow{6}{*}{ 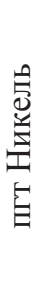 } & \multirow{4}{*}{ Куэтсъярви } & 1 & 6.92 & 10 & 254 & 72 & 15 & 193 \\
\hline & & 2 & 6.74 & 12 & 210 & 12 & 10 & 112 \\
\hline & & 3 & 7.08 & 8 & 267 & 49 & 9,7 & 115 \\
\hline & & 4 & 7.19 & 13 & 246 & 40 & 10.8 & 118 \\
\hline & \multicolumn{2}{|l|}{ LN2 } & 6.60 & 5 & 152 & 0 & 14 & 323 \\
\hline & \multicolumn{2}{|l|}{ LN3 } & 6.61 & 7 & 182 & 1 & 29 & 108 \\
\hline \multirow{6}{*}{ 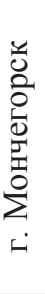 } & \multicolumn{2}{|c|}{ Пыслысчимъявр } & 6.75 & 10 & 614 & 7 & 96 & 211 \\
\hline & \multicolumn{2}{|c|}{ Сопчъявр } & 7.09 & 14 & 810 & 469 & 36 & 215 \\
\hline & \multicolumn{2}{|l|}{ Кумужье } & 6.92 & 11 & 174 & 14 & 26 & 51 \\
\hline & \multicolumn{2}{|l|}{ Нюдъявр } & 8.47 & 51 & 859 & 179 & 106 & 220 \\
\hline & \multicolumn{2}{|l|}{ Травяное } & 7.16 & 14 & 322 & 63 & 148 & 126 \\
\hline & \multicolumn{2}{|c|}{ Комсомольское } & 7.22 & 0 & 432 & 110 & 9.2 & 10 \\
\hline \multirow{7}{*}{ 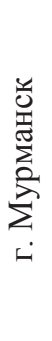 } & \multicolumn{2}{|c|}{ Семеновское } & 6.89 & 23 & 589 & 0 & 3.1 & 3 \\
\hline & \multicolumn{2}{|l|}{ Северное } & 7.04 & 10 & 225 & 1 & 2.7 & 5.9 \\
\hline & \multicolumn{2}{|l|}{ Среднее } & 7.42 & 9 & 401 & 1 & 3.7 & 5.0 \\
\hline & \multicolumn{2}{|l|}{ Ледовое } & 8.71 & 90 & 1600 & 1 & 3 & 13 \\
\hline & \multicolumn{2}{|c|}{ Треугольное } & 6.50 & 20 & 204 & 1 & 1.98 & 3.10 \\
\hline & \multicolumn{2}{|c|}{ Окуневое } & 6.95 & 12 & 437 & 1 & 2.1 & 7.7 \\
\hline & \multicolumn{2}{|l|}{ Южное } & 8.13 & 10 & 288 & 27 & 4.5 & 8.1 \\
\hline \multicolumn{3}{|c|}{ Региональный фон } & 6.80 & 6.00 & 130 & 3.50 & $<1.0$ & $<1.0$ \\
\hline
\end{tabular}

Экстремально высокие для арктической зоны показатели фотосинтетической активности в озерах Семеновское и Ледовое объясняются значительной биогенной нагрузкой при сравнительно низком загрязнении токсичными тяжелыми металлами (табл. 2). В этих озерах в массе развиваются устойчивые к загрязнению представители фитопланктона, предпочитающие эвтрофные воды: в оз. Семеновское - цианопрокариоты (Dolichospermum spp.), в оз. Ледовое - криптомонады (Cryptomonas reflexa Skuja), динофлагелляты (Tyrannodinium edax (A.J.Schilling) Calado) и диатомеи (Diatoma tenuis C.Agardh). Куэтсъярви, самый крупный из изученных водоемов, несмотря на антропогенное эвтрофирование, сохраняет некоторые черты олиготрофных вод в отдельных участках акватории в силу двух основных причин: ингибирования фотосинтетических процессов токсическими компонентами и наличием выраженных водообменных процессов. 


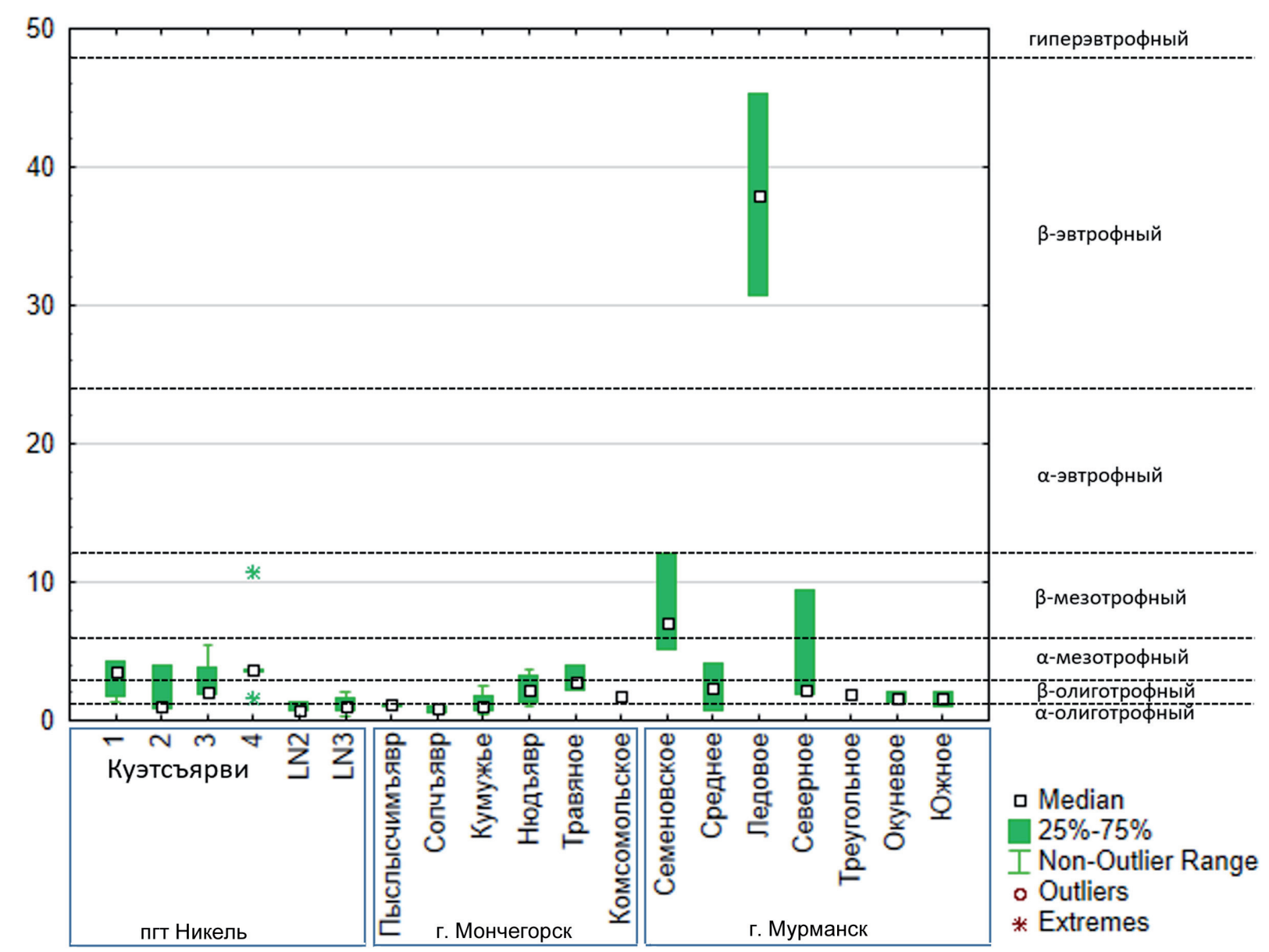

Рис. Содержание хлорофилла «а» (мг/л) в планктоне озер урбанизированных территорий Мурманской области и трофический статус вод (2016-2019 гг.).

Fig. Chlorophyll $a(\mathrm{mg} / \mathrm{l})$ in the plankton of lakes in the urbanized territories of the Murmansk region and the waters trophic state (2016-2019).

\section{Заключение}

В озерах урбанизированных территорий Мурманской области, подверженных интенсивному загрязнению и эвтрофированию, содержание $\mathrm{Chl}$ «a» превышает фоновые для региона показатели и в некоторых водоемах достигает значений, которые экстремально высоки для арктических вод. Несмотря на высокую концентрацию биогенных элементов, большинство озер характеризуется олиготрофным трофическим статусом, как результат угнетения развития водорослей и цианопрокариот, что особенно характерно для небольших озер, подверженных загрязнению предприятиями цветной металлургии АО «Кольская ГМК» пгт Никель и г. Мончегорска. Промежуточное положение занимают водоемы с признаками мезотрофии, где токсическая нагрузка частично компенсируется водообменными процессами в сочетании с эвтрофированием: оз. Куэтсъярви и оз. Нюдъявр. В озерах Ледовом и Семеновском, расположенным в черте г. Мурманска, где биогенные элементы присутствуют в количествах, многократно превышающих фоновые значения, при сравнительно низкой концентрации тяжелых металлов, формируются специфические, не типичные для арктических пресноводных экосистем высокопродуктивные сообщества фитопланктона, способные активно развиваться в летний период. Концентрация Chl «a» в этих озерах достигает экстремальных значений (до 45.3 мг/м³).

Работа выполнена в рамках темы НИР №0226-2015-0001 (отбор проб и интерпретация результатов), а также в рамках гранта РНФ № 19-77-10007 (аналитические исследования и обобщение данных). 


\section{Литература}

1. Баринова С.С. Проблема интегральной оценки токсического влияния на фотосинтетические организмы в водных экосистемах // Водные биоресурсы и среда обитания. 2018. Т. 1. № 1. С. 39-43.

2. Денисов Д.Б. Фитопланктон водоемов Мурманской области в зонах влияния металлургической промышленности // Труды Кольского научного центра РАН. Прикладная экология Севера. 4/2019 (10). Вып. 7. Апатиты: изд. ФГБУН ФИЦ КНЦ РАН. 2019. C. 94-108. DOI:10.25702/KSC.2307-5252.2019.4.94-108.

3. Денисов Д.Б., Кашулин Н.А., Терентьев П.М., Валькова С.А. Современные тенденции изменения биоты пресноводных экосистем Мурманской области. Вестник МГТУ. Т. 12. № 3. 2009. С. 525-538.

4. Денисов Д.Б., Валькова С.А., Терентьев П.М., Черепанов А.А., Разумовская А.В. Экологическая характеристика малых озер в зоне деятельности Мончегорской площадки АО «Кольская ГМК» // Труды Карельского НЦ РАН. Серия Лимнология и океанология. 2018. № 9. С. 65-76. DOI 10.17076/lim845.

5. Китаев С.П. Основы лимнологии для гидробиологов и ихтиологов. Петрозаводск. КарНЦ. 2007.394 с.

6. С.С. Сандимиров и др. // Методы экологических исследований водоемов Арктики. Мурманск. Изд-во: МГТУ. 2019. 180 c.

7. Минеева Н.М. Растительные пигменты в воде волжских водохранилищ. М. Изд-во: Наука. 2004.156 с.

8. Никулина В. Н. Фитопланктон // Биологическая продуктивность северных озер. В 2-х ч. Ч. 2. Озера Зеленецкое и Акулькино. Л. Изд-во: Наука. 1975. С. 37-52.

9. Слуковский 3.И., Денисов Д.Б., Черепанов А.А. Первые результаты обследования озер, расположенных в черте г. Мурманска (июль 2018 г.) // Материалы XXIX молодежной научной школы-конференции «Актуальные проблемы геологии, геофизики и геоэкологии», посвященной памяти члена-корреспондента АН СССР К.О. Кратца и академика РАН Ф.П. Митрофанова. 2018. С. 288-291.

10. Слуковский 3.И., Даувальтер В.А. Морфология и состав техногенных частиц донных отложений оз. Нюдъявр, Мурманская область // Записки РМО. 2019. № 3. С. 102-117. DOI: 10.30695/zrmo/2019.1483.102-117.

11. Черепанов А.А., Денисов Д.Б., Слуковский 3.И., Вандыш О.И., Постнова С.В. Исследования сообществ зоопланктона озер города Мурманска // Труды Кольского научного центра РАН. Прикладная экология Севера. 4/2019 (10). Вып. 7. Апатиты. Изд-во: ФГБУН ФИЦ КНЦ РАН. 2019. С. 83-93. DOI:10.25702/KSC.2307-5252.2019.4.83-93.

12. Determination of photosynthetic pigments in sea water: monography / Rep. of SCOP-UNESCO Working Group 17. Paris, UNESCO. 1996. P. 9-18.

13. Kashulin N.A., Dauvalter V.A., Denisov D.B., Valkova S.A., Vandysh O.I., Terentjev P.M., Kashulin A.N. Selected aspects of the current state of freshwater resources in the Murmansk Region, Russia // Journal of Environmental Science and Health, Part A. 2017. V. 52, No. 9. P. 921-929. DOI 10.1080/10934529.2017.1318633. 